\title{
THE EFFECTS OF ALTHESIN ON ARTERIAL PRESSURE, PULSE RATE PREGANGLIONIC SYMPATHETIC ACTIVITY AND BAROSTATIC REFLEXES IN CATS*
}

\author{
Sanguan Sapthavichaikul, KaJ Wisborg, and Per Skovsted
}

\begin{abstract}
ALTHESIN is a new non-barbiturate intravenous anaesthetic. It is a mixture of two steroid compounds, both rapidly metabolized in the liver. ${ }^{1}$ It has some cardiovascular actions similar to those of thiopentone and methohexitone in that it produces myocardial depression and hypotension ${ }^{2}$ and reduces intracranial pressure and cerebral blood flow. ${ }^{3,4}$ However, it differs from barbiturates in several ways: (1) it has a much higher therapeutic index, (2) it is free from vascular irritation even when administered intra-arterially, and (3) it causes marked tachycardia in therapeutic doses. ${ }^{5}$ Since no studies have been made on the effect of Althesin on central circulatory control mechanisms, we have done so using the same technique as that used in the study of barbiturates. ${ }^{6}$
\end{abstract}

\section{METHOD}

Fourteen cats were used in the experiments. They were initially anaesthetized with halothane by mask while a femoral artery, a femoral vein and the trachea were cannulated. Halothane was then discontinued and 2 to $4 \mathrm{mg}$ of decamethonium was given intravenously and repeated every half hour throughout the experiment. Respiration was controlled with a Phipps and Bird small animal respirator delivering 50 per cent nitrous oxide and 50 per cent oxygen. Total flow to the respirator was 4 litres/min. A 5-litre reservoir bag with pop-off valve was interposed in front of the respirator to permit escape of excess gas. Sympathetic nervous activity was recorded from teased strands of preganglionic fibres of the left cervical sympathetic trunk, divided just below the superior cervical ganglion. Details of the method have been described elsewhere. ${ }^{7}$ To test barostatic reflexes initially and after the administration of Althesin, epinephrine $5 \mathrm{mcg}$ was given intravenously. Only fibres initially showing inhibition in response to the elevation in arterial pressure were studied.

Arterial pressure was sensed by a Statham P-23D transducer (mean pressures obtained by electrical damping). End-tidal $\mathrm{CO}_{2}$ was measured constantly by a Godart capnograph and kept as close as possible to 5.4 per cent with corrections being made for the spectral absorption caused by nitrous oxide. Arterial blood samples were drawn prior to the administration of Althesin and analyzed in an IL assembly for $\mathrm{pH}, \mathrm{PaCO}_{2}$ and $\mathrm{Pa}_{2}$. If metabolic acidosis was present it was corrected with sodium bicarbonate. In all experiments $\mathrm{PaO}_{2}$ exceeded 100 torr. The

"Supported in part by NIH Grant \# HL 15392-03.

From: Department of Anaesthesiology, Hahnemann Medical College and Hospital of Philadelphia, Philadelphia, Pennsylvania 19102, U.S.A. 


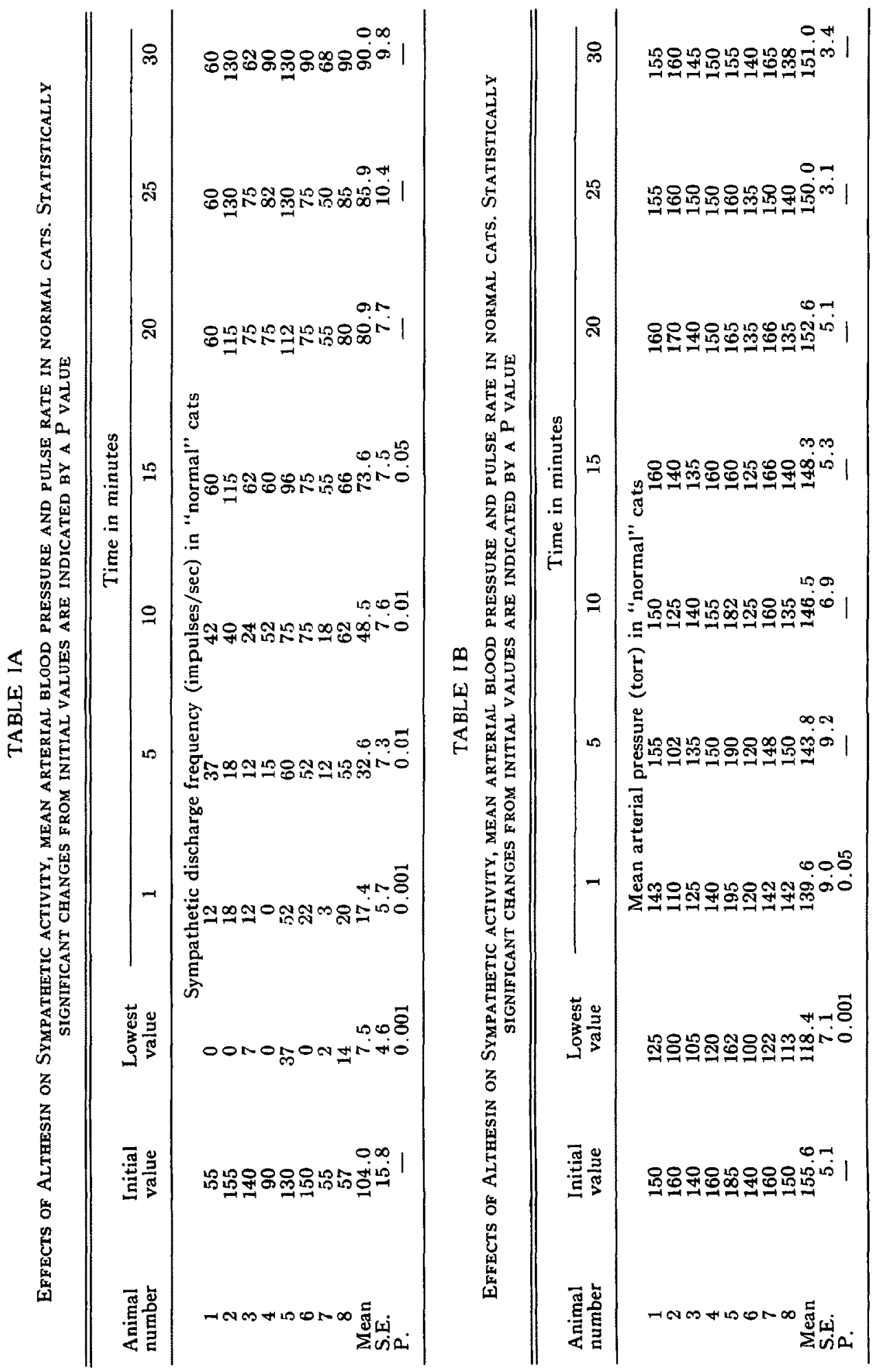


animals were placed on a heating pad so that rectal temperature measured with a Yellow Springs thermister might be kept at $37-38^{\circ} \mathrm{C}$. The following parameters were recorded on a Grass polygraph: arterial pressure, mean arterial pressure, end-tidal $\mathrm{CO}_{2}$, sympathetic nervous activity in impulses per second, and pulse rate measured by a Tachograph triggered by the pulse wave.

\section{Experimental Protocol}

Eight "normal" animals were studied. A "normal" animal is defined as one in which only the sympathetic trunk was sectioned. In three of these barostatic reflexes were tested five minutes after the administration of Althesin by increasing the arterial pressure with epinephrine $5 \mathrm{mcg}$. Four baroreceptor-denervated animals were studied. Each animal received in sequence four injections of Althesin at 30-minute intervals. The carotid sinus, aortic depressor and vagus nerves were sectioned surgically in these animals prior to the administration of Althesin. Two animals were placed in a stereotaxic frame under halothane anaesthesia and midcollicular decerebration was performed by blunt section as the brain stem was approached by gentle retraction on the occipital lobe following the bony tentorium cerebelli. When decerebrate rigidity had occurred the animals were treated as "normals" but received no nitrous oxide. In all instances Althesin was given as a bolus injection intravenously at $0.1 \mathrm{ml} / \mathrm{Kg}$ body weight. All variations are expressed as standard errors of the mean. All statistical analyses were performed using paired t-tests. A $\mathrm{p}$ value below 0.05 was considered statistically significant.

\section{Results}

\section{Normal animals}

The response of sympathetic nervous activity, mean arterial pressure and pulse rate to Althesin are shown in Tables IA, IB, IC and in Figures 1 and 2. After injection of Althesin a marked decline in sympathetic activity was noted from 104.0 \pm 15.8 to $7.5 \pm 4.6 \mathrm{impulses} / \mathrm{sec}(\mathrm{p}<0.001)$. Mean arterial blood pressure declined from $155.6 \pm 5.1$ to $118.4 \pm 7.1$ torr $(p<0.001)$. Simultaneously the pulse rate began to increase and after one minute when sympathetic activity was still depressed to $17.4 \pm 5.7 \mathrm{imps} / \mathrm{sec}(\mathrm{p}<0.001)$ and mean arterial blood pressure also remained somewhat depressed at $139.6 \pm 9.0$ torr $(p<0.05)$, the pulse rate had increased from $182.3 \pm 7.7$ to $204.0 \pm 9.1$ beats per minute $(\mathrm{p}<0.02)$. Mean arterial blood pressure returned to a level not significantly different from the initial level within five minutes, while sympathetic activity was still markedly depressed. Sympathetic nervous activity did not return to a level approximating initial values until 20 minutes after the injection of Althesin. Heart rate returned to normal after 15 minutes.

\section{Denervated animals}

Since Althesin has no cumulative effect ${ }^{4}$ it was feasible to do four experiments in each of the animals studied. The number and sequence of Althesin administrations is described previously in the experimental protocol. 

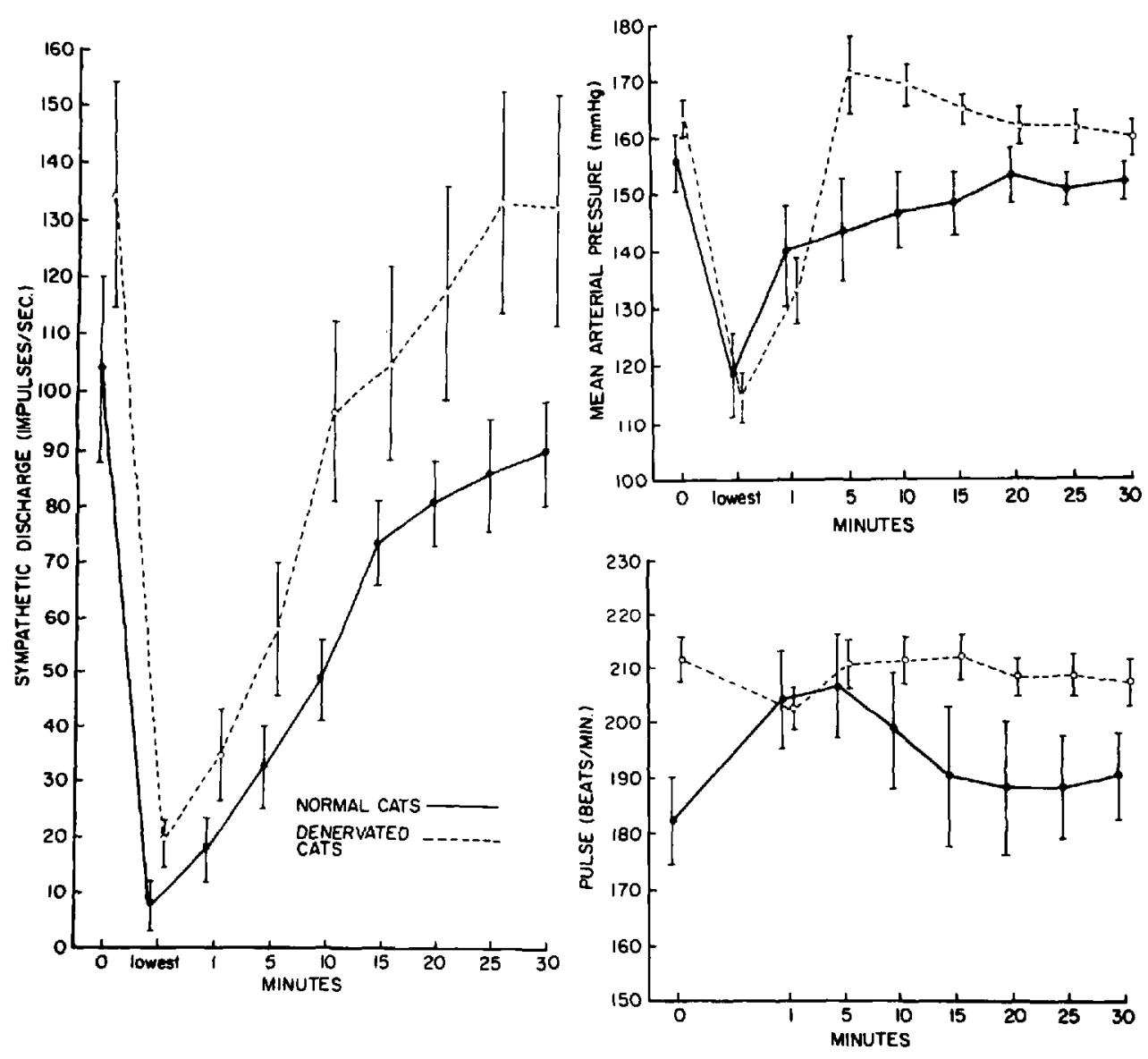

Figure 1. Effects of Althesin on sympathetic nervous activity, mean arterial pressure and pulse rate in normal and baroreceptor denervated cats. (Table I and II in graphic form)

The initial effect of Althesin on sympathetic nervous activity and arterial pressure was similar to that found in normal animals. (Tables IIA,B,C and Figures 1 and 3). Sympathetic nervous activity fell from $134.3 \pm 19.6$ to $18.9 \pm 4.3 \mathrm{imps} / \mathrm{sec}$ $(p<0.001)$ and mean arterial blood pressure from $163.1 \pm 3.3$ to $114.6 \pm 4.3$ torr ( $\mathrm{p}<0.001$ ). The recovery time of the sympathetic nervous activity was 20 minutes as in normal animals; the recovery time of arterial pressure was five minutes. There was, however, one marked difference in the response of arterial pressure from that seen in normal animals, in that an over-shoot in blood pressure was always observed. This occurred in animals 9,10 and 11 after 10 minutes, and in animals 10,11 and 12 after five minutes, a time when sympathetic nervous activity had not returned to normal. Pulse rate declined significantly from $211.6 \pm 4.0$ to $202.3 \pm 3.7$ beats/ min in the first minute $(p<0.001)$ and had returned to the initial level after five minutes. 


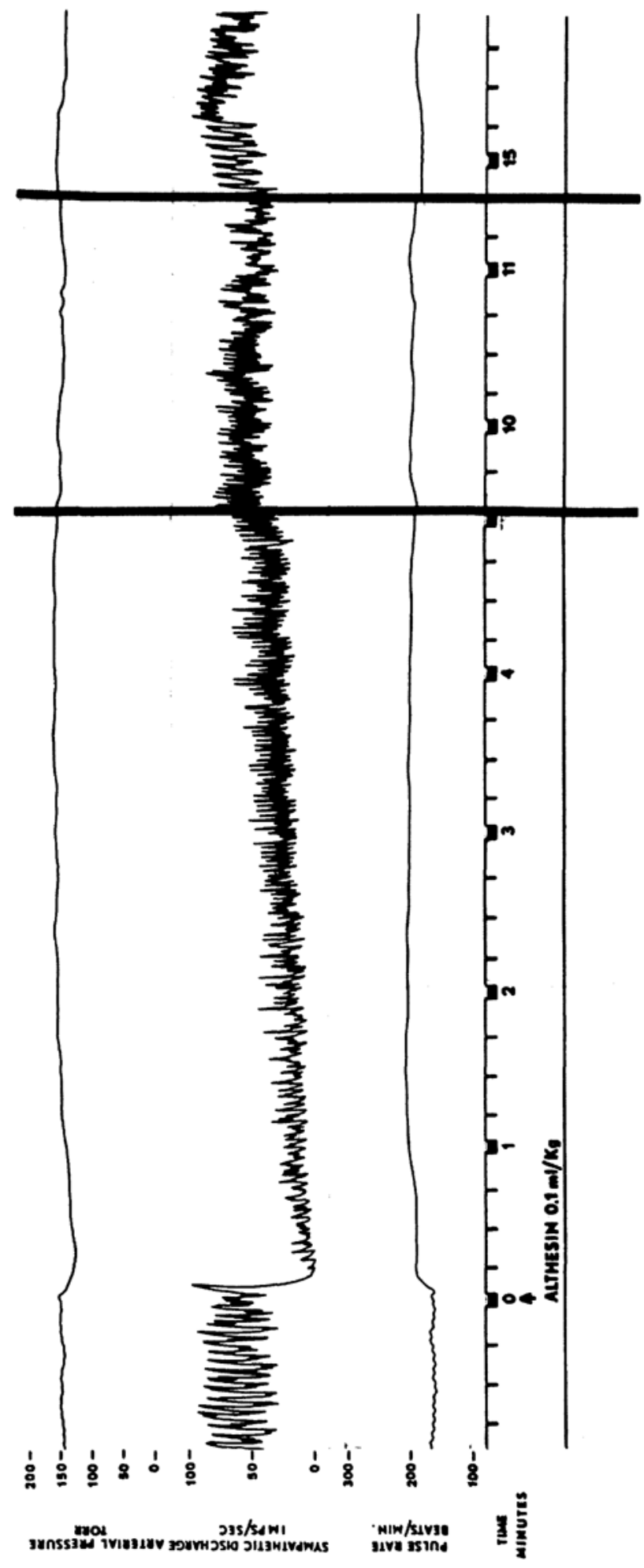

त)

焉

औ

두

跑

过苟 


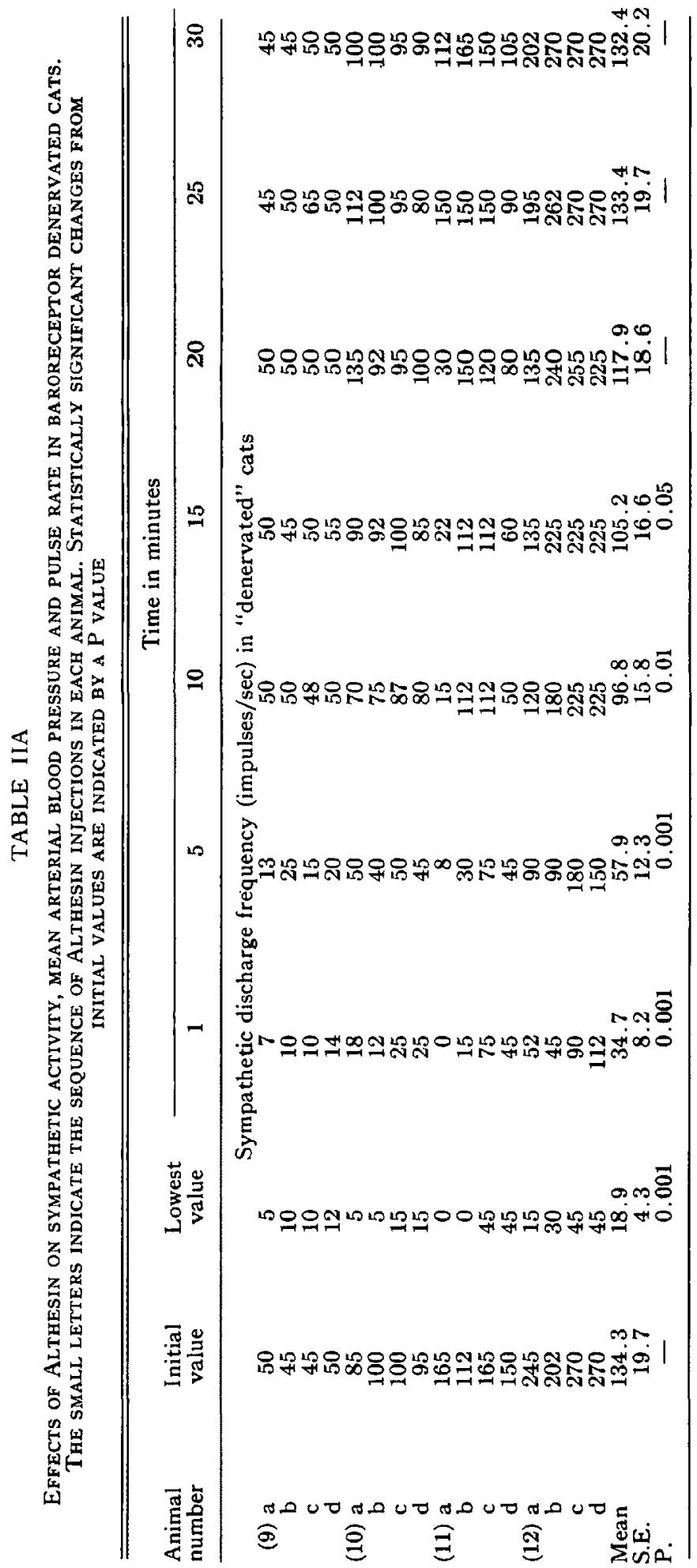




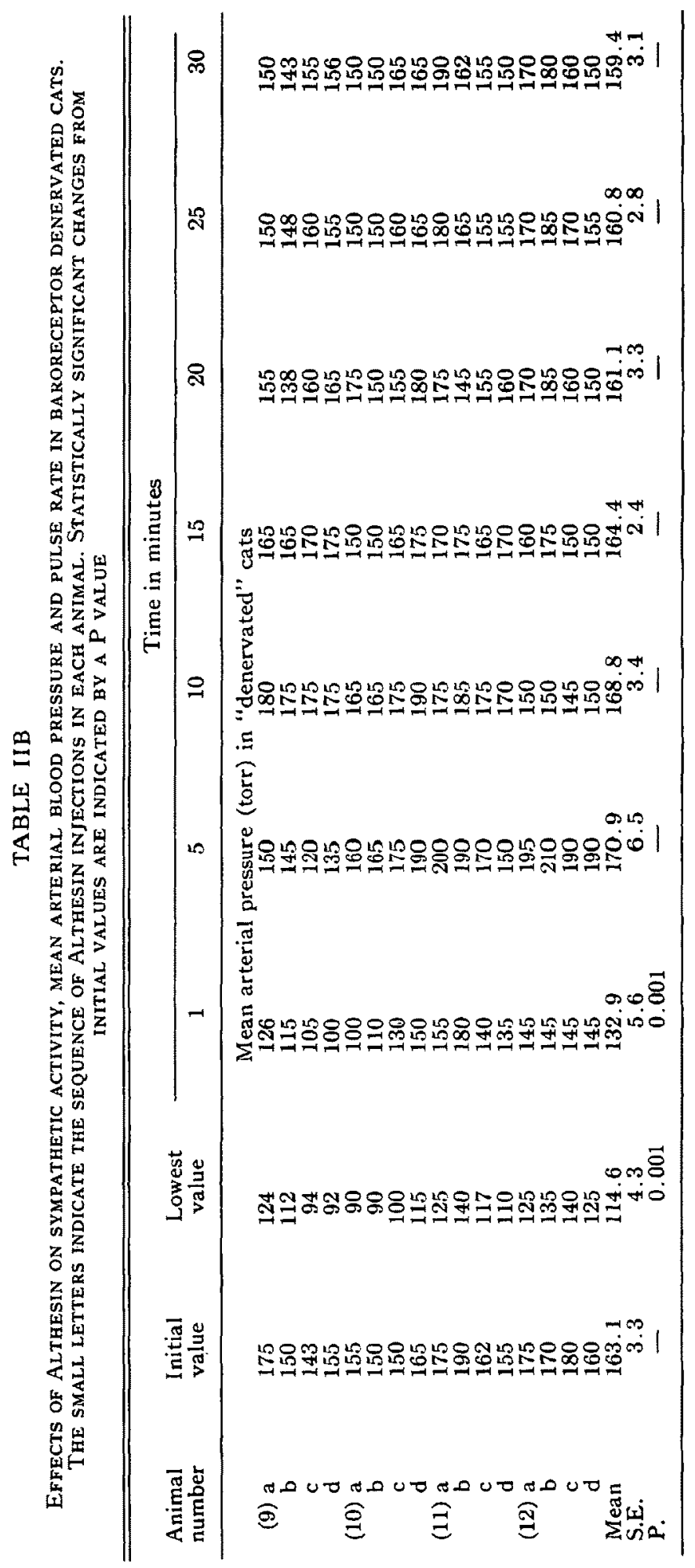




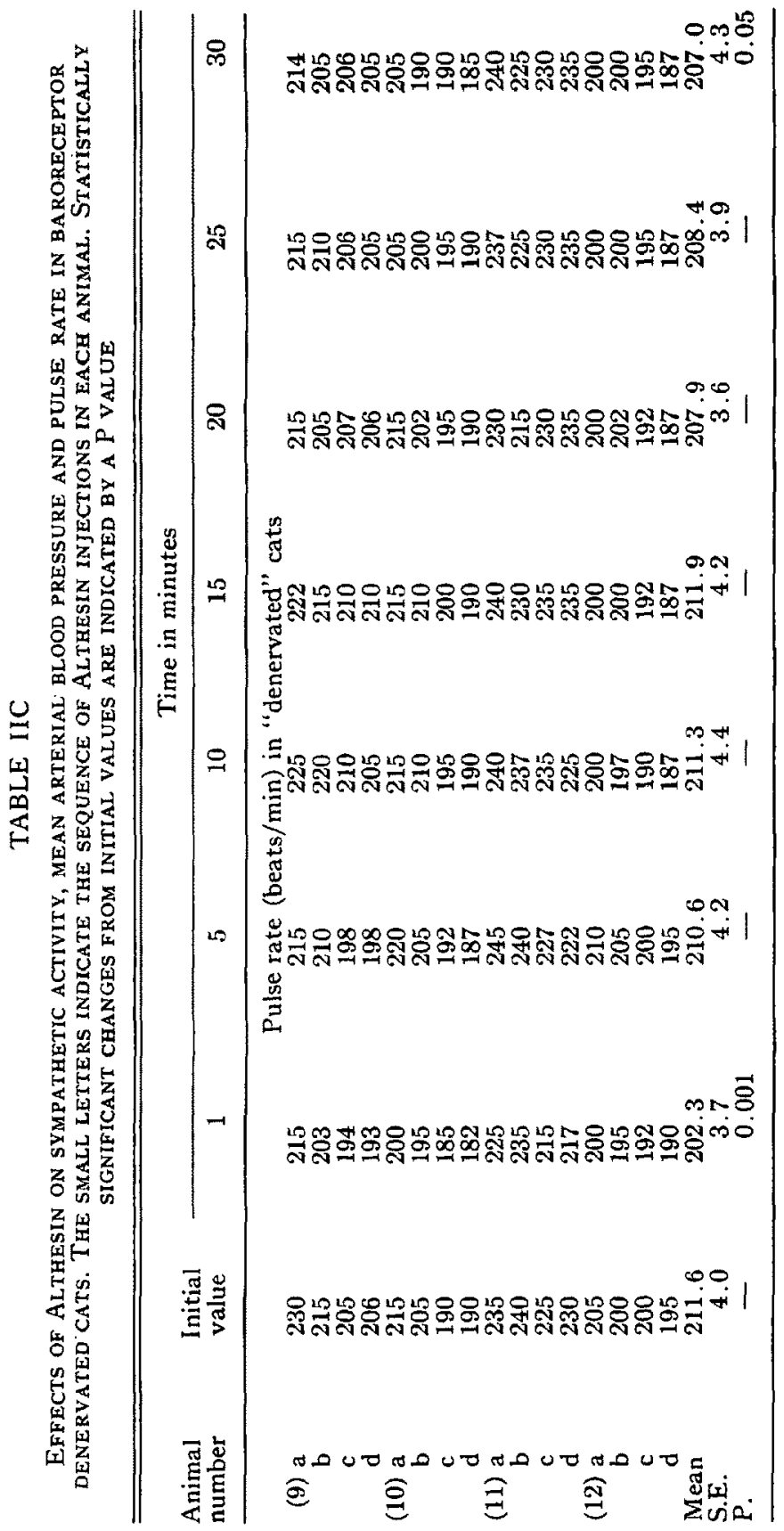




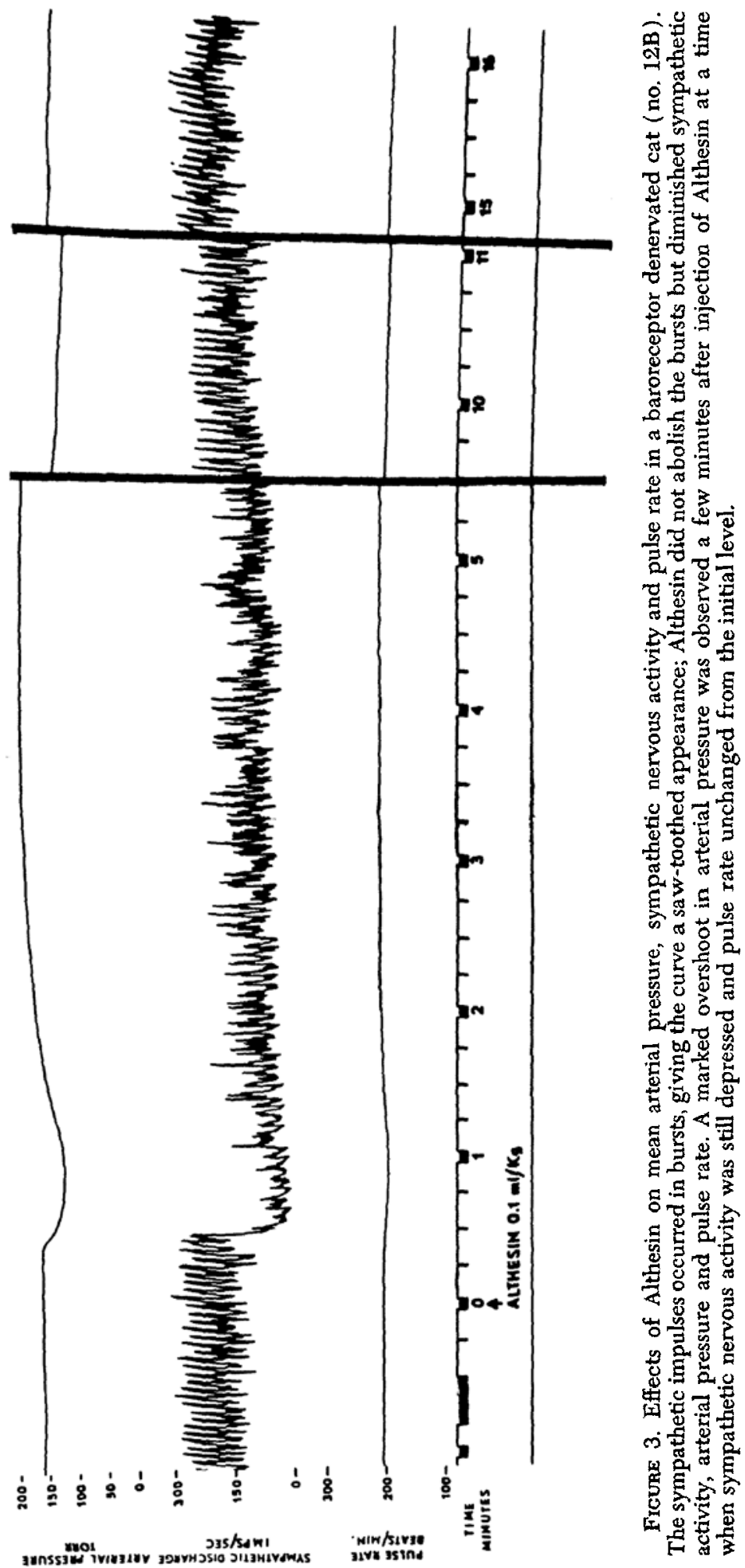




\section{Decerebrate animals}

In one animal the administration of Althesin caused sympathetic activity to fall from 75 to $37 \mathrm{imps} / \mathrm{sec}$, mean arterial blood pressure from 140 to 128 torr and pulse rate to increase from 164 to 176 beats $/ \mathrm{min}$. Return time to controls of sympathetic activity was 18 minutes, of mean arterial blood pressure one minute and of pulse rate 19 minutes. In the other animal sympathetic activity fell from 200 to 135 imps/sec, mean arterial blood pressure from 112 to 99 torr and pulse rate increased from 138 to 145 beats/minute. Return times to normal were nine minutes, four minutes and 12 minutes respectively.

\section{Barostatic reflexes}

Barostatic reflexes were tested by the intravenous injection of epinephrine $5 \mathrm{mcg}$ in animals 6, 7 and 8, five minutes after Althesin; a time when sympathetic activity was still depressed. In all cases the increase in arterial pressure produced a marked decline in sympathetic activity, indicating active barostatic reflexes.

\section{Discussion}

Our primary objective was to study the effects of Althesin on the circulatory control mechanisms by a method previously used in studies of short-acting barbiturates. This would enable us to make a comparison between these two chemically different induction agents. Like barbiturates, Althesin produced a marked depression in sympathetic nervous activity accompanied by a simultaneous decrease in arterial pressure. With short-acting barbiturates the depression in sympathetic activity was found to be a probable cause of the blood pressure decline, since sympathetic nervous activity closely mimicked the changes in arterial pressure during both induction and recovery. ${ }^{6}$ With Althesin the depression in sympathetic activity also accompanied the initial hypotension but, unlike the barbiturates, recovery of arterial pressure after Althesin did not accompany recovery of the sympathetic nervous activity, since arterial pressure returned to normal within a few minutes while the return of sympathetic activity was greatly delayed. Cardiac rate was elevated after Althesin injection, and remained elevated for an intermediate period. Campbell, et al. ${ }^{5}$ showed that Althesin has a vagolytic action, since the tachycardia could be prevented by the previous administration of atropine. This is in agreement with our finding that Althesin only produces tachycardia in normal and not in denervated animals with severed vagi. One might be tempted to assume that the faster recovery of arterial pressure as compared to recovery of sympathetic activity might be due to the tachycardia, but this is ruled out by the fact that denervated animals did not exhibit tachycardia but reacted otherwise in the same way as normal animals. Prys-Roberts and Foëx studied the cardiovascular effects of Althesin on hypertensive patients and found transient hypotension, tachycardia and decreased stroke volume but unchanged cardiac output and total peripheral resistance. ${ }^{8}$ The finding of an unaffected total peripheral resistance is remarkable in view of the observations by Doenicke et al. ${ }^{9}$ that Althesin causes release of histamine and of our findings that there is diminished sympathetic tone, both of which should cause vasodilatation. 
Studying barostatic reflexes in cats, and using Althesin in a dose eight times greater than we did, Dodds and Twissel ${ }^{10}$ found that the reflex bradycardia produced by intravenous administration of epinephrine was greatly reduced or abolished compared to the pre-anaesthetic control. This is in no way in contradiction with our findings of preserved barostatic reflexes as we only administered epinephrine at a time when sympathetic activity was present, which could hardly have been the case after the large dose of Althesin used by Dodds and Twissel. What makes their study so interesting is the finding that the same dose of epinephrine results in a much longer-lasting hypertension after Althesin than during the control period, indicating either a sensitization of adrenergic receptors in the peripheral vasculature or interference with the metabolism and/or re-uptake of the sympathetic humoral transmitter. With this in mind, it now can be explained why arterial pressure returns to normal and total peripheral resistance remains unchanged in spite of decreased sympathetic tone, since the action of the lower sympathetic tone is compensated for by an enhanced action of the released catecholamines. An enhanced action of released catecholamines would likewise explain the overshoot in arterial pressure seen in our denervated animals after the initial brief hypotension caused by the myocardial and sympathetic depressant effect of Althesin. The fact that normal animals seldom showed an overshoot in arterial pressure is in no way in contradiction with an enhanced action of catecholamines, since normal animals had preserved barostatic reflexes which would buffer any tendency to an increase in arterial pressure. Since decerebrate animals responded to Althesin in a manner similar to the normal ones, the site of action for the sympathetic depression is presumably the vasomotor centre in the medulla oblongata.

In its action on the circulatory control mechanisms, therefore, Althesin resembles the short-acting barbiturates in depressing sympathetic nervous activity by an action on the vasomotor centre and preserves barostatic reflexes, but differs from the barbiturates in that the sympathetic depression is counteracted by a vagolytic action of Althesin and enhancement of the action of catecholamines, factors which both serve to restore circulatory homeostasis in spite of a continuing depression of sympathetic nervous activity.

The findings of Child, et al. ${ }^{1}$ that there is no cumulative effect after repeated doses of Althesin was confirmed by our study in denervated animals where arterial pressure, sympathetic nervous activity and pulse rate invariably returned to the initial level after multiple injections.

The clinical implication of our findings is that an extraordinary degree of hypotension is to be expected in individuals relying on high sympathetic tone and/or normal pulse rate to maintain sufficient cardiovascular function. This has already been shown by Harrison and Sellick ${ }^{11}$ in patients with valvular heart disease, where Althesin as induction agent produced a 40 per cent decline in arterial pressure. This should not be unexpected as patients with valvular heart disease are known to respond to tachycardia with decreased cardiac function, including cardiac failure. Patients with high sympathetic tone necessary to maintain circulatory homestasis such as in hypovolaemia or in shock likewise may be expected to have an excessive decline in arterial pressure if anaesthesia is induced with Althesin. 
In sufficient concentrations all commonly used inhalational anaesthetic agents are known to increase intracranial pressure and this might be hazardous during neurosurgical procedures. The findings of Child, et al., ${ }^{1}$ confirmed by our study, that no cumulative effect occurs after repeated doses of Althesin and the fact that Althesin reduces intracranial pressure, ${ }^{4}$ indicate that Althesin either in repeated doses or as an intravenous drip might be an ideal neurosurgical anaesthetic.

\section{SUMMarY}

We have studied the effects of Althesin on preganglionic cervical sympathetic nervous activity, arterial pressure, pulse rate and barostatic reflexes in cats. Normal, baroreceptor denervated and decerebrate animals were studied. On the basis of our finding it is concluded that Althesin severely depresses sympathetic nervous activity by action on the vasomotor centre. The depression of arterial pressure however was only moderate due to two compensatory mechanisms: a vagolytic action of Althesin and a peripheral vascular effect believed to be caused by an enhanced action of catecholamines caused by Althesin. Barostatic reflexes were found active under conditions where Althesin did not totally abolish sympathetic tone.

\section{RÉSUMÉ}

Nous avons étudié les effets de l'althesin sur l'activité nerveuse préganglionnaire cervicale sympathique, la pression artérielle, la fréquence cardiaque et les réflexes des barorécepteurs chez le chat. Les études ont été effectuées chez des animaux normaux, décérébrés et dont les barorécepteurs avaient été dénervés. D’après les résultats, nous pouvons conclure que l'althesin déprime de façon importante l'activité nerveuse sympathique par son action sur le centre vaso-moteur. La diminution de la pression artérielle était cependant peu marquée, due à des mécanismes compensateurs: fréquence d'une action vagolytique de l'althesin et d'un effet vasculaire péripérique possiblement dû à l'action amplifiée des catécholamines causée par l'althesin. Les réflexes à partir des barorécepteurs étaient prẻsents dans les conditions où l'althesin n'avait pas aboli complètement le tonus sympathique.

\section{ACKNOWLEDGMENTS}

The authors would like to acknowledge the assistance of Henry L. Price, M.D. Professor, Chairman and Research Director of the department for his advise during the conduct of the study and in the preparation of the manuscript, the able technical assistance of Mr. Leo Davidson and GLAXO for their supply of Althesin.

\section{REFERENCES}

1. Child, K.J., Currie, J.P., Davis, B., Dodds, M.G., Peance, D.R., \& Twissel, D.J. The pharmacological properties in animals of CT 1341, a new steroid anaesthetic agent. Brit. J. Anaesth. 43: 2 (1971).

2. GoRdH, T. The effect of Althesin on heart in situ in the cat. Postgrad. Med. J. Suppl. (2) 48: 31 ( 1972$)$.

3. Takahashi, T., Takasaki, M., Namiki, A., \& Dohi, S. Effects if Althesin on cerebrospinal fluid pressure. Brit. J. Anaesth. 45: 179 (1973). 
4. Pickenodt, V.W.A., McDowall, D.G., Cononeos, N.J., \& Keaney, N.P. Effect on Althesin on cerebral perfusion, cerebral metabolism and intracranial pressure in anaesthetized baboon. Brit. J. Anaesth. 44: 751 (1972).

5. Campbelx, D., Millen, D.C., \& Bhadford, E.M.W. Althesin: further studies of interaction with anaesthetic agents. Postgrad. Med. J. Suppl. (2) 48: 123 (1972).

6. Skovsted, P., Price, M.L., \& Price, H.L. The effects of short-acting barbiturates on arterial pressure, preganglionic sympathetic activity and barostatic reflexes. Anesthesiology 33: $10(1970)$.

7. Skovsted, P., Price, M.L., \& Price, H.L. The effects of halothane in arterial pressure, preganglionic sympathetic activity and barostatic reflexes. Anesthesiology 31: 507 (1969).

8. Prys-Rogerts, C., FoËx, P., \& Biro, G.P. Cardiovascular response of hypertensive patients to induction of anaesthesia with Althesin. Postgrad. Med. J. Suppl. (2) 48: 80 (1972).

9. Doenicke, A., Lorenz, W., Beigl, R., Bezecny, H., Uhlig, G., Kalmar, L. Praetorius, B., \& MANN, G. Histamine release after intravenous application of short-acting hypnotics. Brit. J. Anaesth. 45: 1097 (1973).

10. Dodos M.G. \& Twissel, D.J. Effect of Althesin (CT 1341) on circulatory responses to adrenaline and halothane-adrenaline cardiac dysrhythmias in the cat. Postgrad. Med. J. Suppl. (2) 48: 17 (1972).

11. Hahrison, S.G.C. \& SEllick, B.A. Cardiovascular effect of Althesin in patients with cardiac pathology. Brit. J. Anaesth. 44: 1205 (1972). 